\title{
Problems faced by Selected Small Business Units in Coimbatore city due to Demonetization
}

\author{
Malarvizhi, V. \\ Department of Economics, Avinashilingam Institute for Home Science and Higher Education for Women, Coimbatore, Tamil \\ Nadu, India
}

Corresponding author: joshmals@gmail.com

\begin{abstract}
Small scale industries has been considered as device of economic growth and development in many developing countries and this constitute the backbone of an economy in maintaining a significant growth and in generating employment opportunities. The Government of India declared that ₹ 500 and ₹ 1000 notes will be no longer legal tender from midnight, $8^{\text {th }}$ November 2016. This move is expected to cleanse the formal economic system, discard black money and counterfeit notes. The small business units who largely depend on Cash related transaction on daily basis witnessed more disturbances. Therefore an attempt has been made to identify the problems faced by the small business units and give suggestions to improve the working of small business units which were affected by demonetization in Coimbatore city. The study revealed that most of the respondents were unhappy about the implementation of demonetization because they faced loss due to cash crunch and had a great impact on their small business activities and their standard of living.
\end{abstract}

Keywords: Demonetization, Black Money, Small Business Units, Tax Evasion, Cash Crunch \& Corruption.

In a developing country like India, the role and importance of small-scale industries is very significant towards poverty eradication, employment generation, rural development and creating regional balance in promotion and growth of various development activities. It is estimated that this sector has been contributing about $40 \%$ of the gross value of output produced in the manufacturing sector and the generation of employment by the small-scale sector is more than five times to that of the large-scale sector. About 60 to 70 percent of the total innovations in India come from the SSIs. Many of the big businesses today were all started as small units and then nurtured into big businesses.

Shocking official announcement made by the Government of India on $8^{\text {th }}$ November 2016, for demonetization of the high value currencies of ₹ 500 and $₹ 1000$ with an objective to curb the black money and the corruption, counterfeit currency as well as terror funding. This decision is considered as biggest cleanliness drive against the black money in the history of Indian economy whose benefits will be reaped in the long run. However, the impact of this abrupt move is causing major cash crunch in the economy affecting day to day requirements of the common man and businesses.

Demonetization drive has impacted the Indian businesses directly or indirectly in terms of impact on demand but the impact of demonetization is majorly seen on small businesses as these are highly driven by cash transactions. The labour-intensive sectors mainly agriculture and construction sector have been impacted since a major portion of transactions involve cash for the purchase of raw materials and payment to daily wage labourers. SMEs sector has been impacted significantly as the sector is majorly driven by the contractual and daily wage work force and most of the mobile work force doesn't have their bank accounts at the place of their working.

Ever since the onset of the financial crisis, the economy has been struggling to revive itself and 
achieve a healthy growth rate. The growth of SSIs depends on capital investment to a great extent and if there is lack of flow of capital its growth will be stunted. Demonetization has brought in financial crunch and has limited the growth of the sector. Small scale industries are playing a stellar role in the economic development of the country but the problems in performing the functions after demonetization is the major hurdle in their development. Thus there is a need to examine the "Problems faced by selected small business units in Coimbatore district due to demonetization" and its performance before and after introduction of demonetization. The specific objectives of the study are (1) to study the socio-economic profile of the SBUs respondents; (2) to identify the problems faced by the SBUs due to demonetization and (3) to give valuable suggestions to improve demonetization effects.

\section{Literature Studies}

Sharma and Gupta, (2017), studied the impact of demonetization on MSME sector and found that MSME sector was hardly hit by demonetization due to their greater dependence on hard cash. Construction sector and roadside vendors seems to be worst hit. A survey done during demonetization days in Ghaziabad city on retail sector by Vij, (2017) found that demonetization impacted retail sector very badly especially the small vendors (Rehdiwala) who were totally depended on cash. Frank et al. (2017) expressed that demonetization is a replacement of old currency unit with a new currency unit, here old currency are retired and replaced with a new currency. The impact of demonetization on the small scale retailers were studied in Moodbidri city and it was found that overall retailers were happy with the Demonetisation effect.

Tiwari1 and Tiwari (2017), analyzed that in Indian economy small-scale and cottage industries occupy an important place, because of their employment potential and their contribution to total industrial output and exports. Small scale industries are largely dependent on cash in comparison to large scale industries where transactions can be made cashless. Demonetization has created a cash crunch that has sent the small scale units into disarray. Demonetization move has threatened large scale unemployment in small industries sector. The associated chambers of commerce in India (ASSOCHAM) president said that demonetization has negative impact as well because industries are suffering and people are losing jobs. The study elucidated the role of small scale industries in employment generation and effects of demonetization in creating unemployment in these industries. The study analyzed secondary data source and the same has been verified by the primary data analysis.

Mathur and Arora (2017), elucidated that the $8^{\text {th }}$ November, 2016 is the important date in the history of the Indian economy, when our honorable Prime Minister Narendra Modi announced the decision to demonetize the 500 rupee note and 1000 rupee note. It was a surprise move that has affected the consumption activity in the Indian economy. The move has affected the Indian retail sector due to lack of liquidity in the economy. It has also resulted in the low foot fall in shopping malls, more use of plastic money and electronic payment. The impact is felt more by the small traders and the unorganized retailing segment as their transaction is in cash. But it is estimated that Indian economy can grow considerably after curbing the counterfeit money and increase in the economic activity. The study analyzed the impact of demonetization on the Indian retail sector both organized and unorganized.

\section{Methodology}

Multi stage sampling design was adopted in the study for selecting the sample. Sixty samples were selected from the universe by adopting incidental purposive sampling technique. The required data was collected by administrating a pre-tested interview schedule during the period July 2018. Besides averages, and percentages, techniques Likert's summated scale and factor analysis were used.

\section{RESULTS AND DISCUSSION}

Socio-economic status refers to a graded hierarchy of social positions which can be used to describe a person's overall social position or standing. It can be indicated by a number of sub-concepts such as age, gender, occupational status, educational attainment, and income and wealth. Hence for predicting, the behaviour of people socio-economic status as measured by the researcher. The present 
study assessed the socio-economic status on the basis of age, gender, marital status, education, Area of dwelling, type of family, occupation and income of the sample respondents. A total of 60 respondents were surveyed. The study observed that majority of the respondents were male dominated (65 percent) and the remaining 35 percent were females. Age is an important socio-economic factor which determines individual's standard of living and attitude. Majority of the respondents were in the younger and effective category. Marital Status shows that majority of them were married (75 percent). Education is the main influencing factor in socio-economic status to fulfil all needs of the respondents.

The study could be observed that majority of the respondents were educated and only few of the respondents were illiterates. Nearly 42 percent were graduates; while 33 percent have completed primary education; nearly 17 percent did higher secondary education and rest 8 percent were illiterate. Type of family: majority of the respondents (nearly 52 percent) were in nuclear family and 48 percent of them lived in joint family.

Since the representation by the respondents on nuclear family and joint family was almost equal it inferred that family does not play any role among the selected respondents for this particular study. Area of dwelling of the respondents were studied and it showed that, nearly 57 percent of them were living in urban area; followed by 33 percent living in semi-urban and remaining 10 percent living in the rural area.

Since the respondents were from urban area, most of them could earn higher level of income compared to the respondents from semi-urban area. Occupational status shows majority of the respondents (28 percent) were doing the job of vegetable vending followed by 20 percent of them occupied in running baby shops.

Further 10 percent each of the respondents were running medical shop and textiles and boutiques to earn their living. Income details of the sample reports that around 50 percent of the respondents were seen earning between ₹ 25,000/- ₹ 50,000/per month. It was surprising to note that around 30 percent of them could earn between ₹ 50,000/₹ 75,000/- which indicates that respondents were sincere and hard working in their activities.
Since small scale businesses are the backbone of the economy, the present study made an attempt to study to analyze the problems faced by small scale industries due to implementation of demonetization. Factor analysis was used in the study to identify the problems faced by the respondents due to demonetization and whether these problems can be grouped in terms of a composite variable. To determine the appropriateness of applying factor analysis, the KMO and Bartlett's test measures were computed and the results are presented in Table 1.

Table 1: KMO and Bartlett's Test Measures

\begin{tabular}{cc}
\hline KMO measures & 0.451 \\
Bartlett's test of Sphericity: approx: chi-square & 200.914 \\
Degrees of freedom & 91 \\
Significance & .000 \\
\hline
\end{tabular}

Source: Estimation based on field survey.

KMO statistics for respondents were 0.451 signifying higher than acceptable adequacy of sampling. The Bartlett's test of sphericity was also found to be significant at one percent level providing evidence of the presence of relationship between variables to apply factor analysis. The communalities for each variable were computed to determine the amount of variance accounted by the variables to be included in the factor rotations.

All the variables had values greater than 0.50 signifying substantial portion of the variance accounted by the factors. Table 2 presents the Eigen values, their relative explanatory powers and factor loadings for 12 linear components identified within the date set. The Eigen value greater than one alone was considered for inclusion in the analysis.

The results indicates that for the sample data, Eigen value of the first six factors alone was greater than one for the respondents indicating that these factors alone were appropriate for inclusion in the analysis and these six factors together accounted for 71 percent of the variations in the factors.

Factor 1 has significant loadings for two dimensions namely 'Long Queues and Waiting Hours' and 'Payment Problems to Suppliers'. These two dimensions together explained 13 percent of the variance.

Factor 2 has significant loadings for three dimensions namely 'Unavailability of Cash at Banks and ATM's' 
Table 2: Rotated Component Matrix

\begin{tabular}{|c|c|c|c|c|c|c|}
\hline \multirow[t]{2}{*}{ Problems } & \multicolumn{6}{|c|}{ Components } \\
\hline & 1 & 2 & 3 & 4 & 5 & 6 \\
\hline Long Queues and Waiting Hours & .874 & & & & & \\
\hline Payment Problems to Suppliers & .686 & & & & & \\
\hline Unavailability of Cash at Banks and ATM's & & .783 & & & & \\
\hline ATM's Closed & & .759 & & & & \\
\hline Long Queues at Banks & & .516 & & & & \\
\hline Lack of ATM's Centre & & & .890 & & & \\
\hline People Who Do Not Have Bank Accounts & & & .806 & & & \\
\hline Lack of Sales & & & & .808 & & \\
\hline $\begin{array}{l}\text { Scarcity of Smaller Currency } \\
\text { Demonetisation }\end{array}$ & & & & .710 & & \\
\hline Limits of Transactions Per Day/ Amount & & & & & .854 & \\
\hline Mismanagement at the Banks & & & & & .822 & \\
\hline Daily Wage Labourers who lost their Jobs & & & & & & .843 \\
\hline Eigen Values & 1.851 & 1.814 & 1.682 & 1.654 & 1.534 & 1.436 \\
\hline Percentage of Variance & 13.223 & 12.955 & 12.014 & 11.816 & 10.960 & 10.255 \\
\hline Percentage Cumulative & 13.223 & 26.178 & 38.192 & 50.008 & 60.968 & 71.223 \\
\hline
\end{tabular}

Source: Estimation based on Field Survey, Extraction method: principal component analysis, Rotation method: Varimax with Kaiser Normalization, rotation converged in 7 iterations.

and 'ATM's Closed' and 'Long Queues at Banks' and explained nearly 13 percent of the variance. Factor 3 has significant loadings for two dimensions namely 'Lack of ATM's Centre' and 'People Who Do Not Have Bank Accounts' and explains 12 percent of the variance. Factor 4 has significant loadings for two dimensions namely 'Lack of Sales' and 'Scarcity of Smaller Currency Demonetisation' and explains nearly 12 percent of the variance. Factor 5 has significant loadings for two dimensions namely 'Limits of Transactions per Day/ Amount' and 'Mismanagement at the Banks' and explains nearly 11 percent of the variance. Factor 6 has significant loadings for only one dimension namely 'Daily Wage Labourers Who Lost Their Jobs' and explains nearly 10 percent of the variance. To conclude it could be observed that introducing demonetization by the government of India created turmoil in short period as most people faced difficulties like exchanging old currencies in long queues at banks, non-availability of smaller denominations currency and lack of ATMs centers across the country. If these problems are solved by the government, demonetization would bring a positive strength on economy as it encourages the digital mode of payment increasing the ATMs centers in and around rural and semi urban areas.
Suggestions from any corner would always help the government or those in authority to take stock of the situation and bring the required changes in the system. The current study also invited suggestion from the respondents, on the impact of demonetization. They gave positive suggestions on demonetization and stated that it helps the country to curb black money, corruption and tax evasion for the betterment of society and the future growth and progress of the country. Demonetization mainly affects people in rural areas where there is lack of ATM machines therefore they have to stand in long queues and withdraw money for their daily life. It affects the small business firms and thereby incur huge financial loss and daily wage earners loss their job due to cash crunch. The table shows the attitude of the respondents.

Table 3: Attitudes towards for Demonetization

\begin{tabular}{ccc}
\hline Attitudes & Frequency & Percentage \\
\hline Favour of demonetization & 15 & 25.00 \\
Not in favour of demonetization & 44 & 73.33 \\
Neutral & 01 & 1.66 \\
\hline
\end{tabular}

Source: Estimation based on Field Survey.

Table 3 shows that most of the respondents $(73$ percent) were unhappy about the implementation of 
demonetization because they faced loss due to cash crunch. Due to this cash crunch most of the daily wage earners were removed from the work in rural areas. Most of them didn't have the bank account in their names and were unaware about the digital mode of payment system. Twenty five percent of them were in favour of demonetization because they wished to eliminate the black money and corruption, move towards a digitalized economy which can bring transparency in the system and less chance of avoiding the taxes. However, most of them felt that demonetization affects their small business activities and their standard of living.

\section{CONCLUSION}

The decision of demonetization was widely accepted by the people in order to bring more transparency and accountability in the economic and political system. Due to wrong planning and implementation of demonetization, the people who operate on small scale industries were hit the most because their sales fell down, they faced huge financial losses and most of them closed down their units in Coimbatore city. The study found that, most of the respondents were unhappy about sudden changes in the monetary system in the economy. For this, the government should take initiative to educate and create more awareness and usages of digitalization in the rural areas and further the government can promote and make available more online facilities to small business people.

\section{REFERENCES}

Devendra Kumar Tiwari \& Deepika Tiwari 2017. Effect of Demonetization on Employment Generation in Micro, Small and Medium Enterprises. International Journal of Current Trends in Engineering \& Technology, 03(05): 279-284.

Gupta, A.S. 2017. “Impact of Demonetization on MSME. International conference on Paradigm shift in World Economies: Opportunities and Challenges Delhi, pp. 102-105.

Parthajeet Das 2017. Micro, Small and Medium Enterprises (MSME) in India: Opportunities, Issues \& Challenges. Great Lakes Herald, 11(1): 77-88.

Purvi Mathur \& Ritu Arora. 2017. Impact of demonetization on the Indian retail industry before and after $10^{\text {th }}$ December, 2016. International Journal of Development Research, 7(7): 13993-13999.

Reema Agnes Frank, Alisha, A.F. and Rashmi Kodikal 2017. Impact of Demonetisation on the Small Scale Retailers in Moodbidri City. The National conference on 'Small and Medium Enterprises - Opportunities and Challenges in Digital India' held at Silicon City College, Bangalore on March $18^{\text {th }}$.

Vij, D. 2017. Impact of Demonetization on Retail sector. International Proceedings on Paradigm Shift in World Economies: Opportunities and Challenges, Delhi, pp. 86-90.

Vijayaveelamegavarman, Durga \& Sundaramoorty, K. 2017. Demonetization: Impact on Small Business. National Conference on Impact of Indian 500 \& 1000 Rupee Note Demonetisation (NCIRD-17), Joseph Arts and Science College, Thirunavalur, Tamil Nadu on $11^{\text {th }}$ Feb 2017, pp. 27-29. 
